http://jmscr.igmpublication.org/home/ ISSN (e)-2347-176x ISSN (p) 2455-0450 crossref DOI: https://dx.doi.org/10.18535/jmscr/v7i8.83

\title{
Thyroid Function Abnormalities in patients with Diabetes Mellitus Type II: A comparative Study
}

\author{
Authors \\ Radhika Manjeshwar (M.B.B.S.) ${ }^{1}$, Dikshitha Yogish (M.B.B.S.) ${ }^{2}$, \\ Sweekar Tanugula (Senior Data Scientist) ${ }^{3}$ \\ ${ }^{1}$ Medical Officer, Primary Health Center Edu, Karnataka, India \\ ${ }^{2}$ Medical Officer, Primary Health Center Naravi, Karnataka, India \\ ${ }^{3}$ GE Health Care
}

\begin{abstract}
Introduction: Diabetes mellitus (DM) is fast spreading in developed as well as developing world. With improvements in socioeconomic status and a sedentary life style more and more people are getting affected at a relatively younger age. There are various studies which have reported that there is an increased incidence of thyroid abnormalities in patients with diabetes mellitus. Moreover, presence of thyroid abnormalities is associated with poor metabolic control. Therefore we conducted this study to compare thyroid function in patients with diabetes mellitus type II and healthy individuals.

Materials and Methods: This was a case control study in which 80 patients with Diabetes Mellitus Type II and 80 age matched healthy individuals were included on the basis of a predefined inclusion and exclusion criteria. A detailed history was taken in all the cases with particular attention on duration of diabetes mellitus and presence of other systemic illnesses. Patients were classified as to be having subclinical hypothyroidism (TSH- 4.5 to 10 and normal free T4), Overt hypothyroidism (TSH more than 10 with low free T4 levels), hyperthyroidism (TSH less than 0.45 and raised free T4) and subclinical hyperthyroidism (TSH less than 0.45 and raised free T4). For statistical purposes $p$ value less than 0.05 was taken as statistically significant.

Results: Out of total 160 individuals enrolled in this study there were 92 (57.50\%) females and 68 (42.50\%) males with a M:F ratio of 1:0.73. The age groups were found to be comparable and there was no statistically significant difference in mean age of both the groups $(p=0.53)$. The comparison of the patients of both the groups on the basis of whether they had a normal or abnormal thyroid function test showed that patients with diabetes mellitus type 2 were more likely to be having abnormal thyroid function test as compared to healthy individuals and the difference was found to be statistically significant $(p=0.043)$.

Conclusion: Thyroid abnormalities are more common in patients with diabetes mellitus type II as compared to age matched healthy individuals. It is there for important from point of view of a treating physician to screen patients with DM type II for presence of thyroid function abnormalities.

Keywords: Diabetes Mellitus Type II, Thyroid function abnormalities, Free T4, TSH.
\end{abstract}

\section{Introduction}

Diabetes mellitus is a group of metabolic disorders characterized by hyperglycemia due to either defective insulin secretion or action of insulin, or both. This defective insulin secretion or defect in its action on cellular level have profound effect on carbohydrate, lipid as well as protein metabolism ${ }^{1}$. Diabetes mellitus can be called a 
true pandemic. Centre for Disease Control and Prevention (CDC) report estimated that in the United States 30.3 million had diabetes mellitus. With improvements in socioeconomic status and sedentary life style there is a growing number of individuals getting afflicted with obesity even in developing countries including India. By an estimate, the population with diabetes in India will reach 69.9 million by 2025 and 80 million by $2030^{2}$.

The classical symptoms of diabetes mellitus include polyuria, polydipsia, polyphagia and weight loss. In patients with prolong duration of diabetes symptoms, end-organ damage such as diminished vision (due to retinopathy), paresthesia (neuropathy) or chronic renal failure (nephropathy) may develop ${ }^{3}$. Unlike patients with type I diabetes, patients with type II diabetes may be asymptomatic for prolonged duration before the symptoms appear. Hence there is usually delay in the diagnosis of type II diabetes mellitus ${ }^{4}$. Because of this every newly diagnosed type II diabetes mellitus patients needs to be subjected to investigations (fundoscopy, urine albumin and glycosylated Hemoglobin levels). These investigations might point towards possibility of long duration of diabetes before the patient was finally diagnozed ${ }^{5}$. Uncontrolled diabetes mellitus has a devastating effect on health and well-being of individuals. Uncontrolled diabetes is associated with increased risk of nephropathy, neuropathy and retinopathy ${ }^{6}$. Moreover, the risk of events such as stroke, myocardial infarction and blindness is considerably increased in individuals with diabetes mellitus ${ }^{7}$. Even a tight glycemic control can only delay the onset of end-organ damage.

The association of thyroid dysfunction and diabetes mellitus is complex and has been a topic of interest amongst various researchers including physicians, endocrinologists and diabetologists alike. In 1927 Coller et al reported that hyperthyroidism cause deranged glucose tolerance as well as diabetes in patients. They further reported great improvement in glycemic control as well as diabetic symptoms after thyroidectomy in these patients. Since then, a number of researchers have reported abnormalities of thyroid function in patients with diabetes, and they have also reported worsening of diabetes in patients with thyroid dysfunction. The prevalence of thyroid abnormalities in adult non-diabetic population is reported to be around 6-7\%. As compared to the adult non-diabetic population, in the adult diabetic population the prevalence of thyroid abnormalities is reported to be approximately $12-15 \%$. Females are reported to be affected more commonly compared to males 9 . Though the exact cause of thyroid dysfunction in patients with diabetes is unknown, autoimmunity has been reported to be one of the major cause. This is substantiated by the fact, that Hashimoto's thyroiditis (causing hypothyroidism) as well as Grave's disease (causing hyperthyroidism) both are common in these patients ${ }^{10}$.

We conducted this case control study to find out presence of thyroid dysfunction in patients with Type II diabetes mellitus.

\section{Materials and Methods}

This was a prospective case control study conducted in the primary health care centerin rural area. In this study 80 patients with Diabetes Mellitus Type II and 80 age matched healthy individuals were included on the basis of a predefined inclusion and exclusion criteria. Demographic details such as age, gender, height, weight and BMI were noted in all the cases. A detailed history was taken in all the cases with particular attention on duration of diabetes mellitus and presence of other systemic illnesses such as hypertension, chronic obstructive airway diseases etc. The medication history as well as the type of oral hypoglycemic drugs or insulin that the patient was taking was noted. In order to ensure that there is no confounding variables, patients history of any drug intake which is known to cause altered thyroid function such as amiodarone, lithium, iodine etc. was specifically asked for and if any patient was found to be on this drug then 
such patient was excluded from the study. Study also excluded patients who were pregnant. A thorough general and systemic examination was done in all the cases. All previous investigations such as fasting and post-prandial blood sugar levels, glycosylated hemoglobin level and fundoscopy (if available) was noted. Complete blood count, random blood sugar level and glycosylated hemoglobin was also done if recent investigations were not available. Other than this, serum free T4, TSH, lipid profile and serum creatinine was done in all the cases. Patients were classified into four categories namely subclinical hypothyroidism (TSH- 4.5 to 10 and normal free T4), Overt hypothyroidism (TSH more than 10 with low free T4 levels), hyperthyroidism (TSH less than 0.45 and raised free T4) and subclinical hyperthyroidism (TSH less than 0.45 and raised free T4). The data was analyzed using statistical software SSPS 17.0 software. Two tailed Fisher's exact test and paired t-test were used to determine whether the difference was significant or not. For statistical purposes $\mathrm{p}$ value less than 0.05 was taken as statistically significant.

\section{Inclusion Criteria}

\section{Cases}

1) Individuals having fasting blood sugar level more than $140 \mathrm{mg} / \mathrm{dl}$ and postprandial blood sugarn level more than $200 \mathrm{mg} / \mathrm{dl}$ on minimum 2 separate occasions was labelled as diabetic and 80 such individuals were included in Group A (cases) whereas 80 age matched individuals with normal blood sugar levels were included in group B (Control)

2) Patient consent to be part of study was obtained

3) Age group of 30- 55 years

4) Study only included patients with normal blood pressure

\section{Control}

1. Age matched healthy individuals who consented to be part of study.

\section{Exclusion Criteria}

1) Those who refused consent

2) Patients with uncontrolled hypertension

3) Presence of autoimmune disorders, immunocompromised individuals, patients with hepatic or renal failure

4) Patients with known thyroid disorders

5) Patients on medications such as lithium, amiodarone, iodine etc.which are known to alter thyroid function

6) Pregnant and lactating women

\section{Results}

Out of total 160 individuals enrolled in this study there were $92(57.50 \%)$ females and $68(42.50 \%)$ males with a M:F ratio of 1:0.73. The analysis of gender distribution amongst group A and group B showed that it was comparable and there was no statistically significant difference in the gender distribution amongst 2 groups.

Table1: Gender distribution amongst the studied cases. 2-Tailed Fisher Exact test showed the difference to be non-significant $(\mathrm{P}>0.05)$.

\begin{tabular}{|l|c|c|c|c|}
\hline \multirow{2}{*}{ Age Group } & \multicolumn{2}{|c|}{ Group A } & \multicolumn{2}{c|}{ Group B } \\
\cline { 2 - 5 } & $\begin{array}{c}\text { No of } \\
\text { Patients }\end{array}$ & Percentage & $\begin{array}{c}\text { No of } \\
\text { Patients }\end{array}$ & Percentage \\
\hline Males & 36 & $22.50 \%$ & 32 & $20.00 \%$ \\
\hline Females & 44 & $27.50 \%$ & 48 & $30.00 \%$ \\
\hline Total & 80 & $50 \%$ & 80 & $50 \%$ \\
\hline P=0.631 (Not Significant) & \multicolumn{3}{|c|}{} \\
\hline
\end{tabular}

Age Distribution of the studied cases showed that the most common age group in Group A (Diabetes mellitus type II) was $46-50$ years $(16.88 \%)$ followed by 41-45 years (13.75\%) and51-55 years
(12.50\%). In group B (healthy Individuals) the most common age group was found to be $46-50$ years $(19.38 \%)$ followed by $51-55$ years $(13.13 \%)$ and $41-45$ years $(11.88 \%)$. The mean age of group 
A and group B was found to be $46.53+/-5.35$ and $47.02+/-5.10$ respectively. The age groups were found to be comparable and there was no

Table 2: Age group of the studied cases. Paired T test showed difference to be non-significant $(\mathrm{P}>0.05)$

\begin{tabular}{|l|c|c|c|c|}
\hline \multirow{2}{*}{ Age Group } & \multicolumn{2}{|c|}{ Group A } & \multicolumn{2}{c|}{ Group B } \\
\cline { 2 - 5 } & No of Patients & Percentage & No of Patients & Percentage \\
\hline 35-40 years & 11 & $6.88 \%$ & 9 & $5.63 \%$ \\
\hline 41-45 years & 22 & $13.75 \%$ & 19 & $11.88 \%$ \\
\hline 46-50 years & 27 & $16.88 \%$ & 31 & $19.38 \%$ \\
\hline 51-55 years & 20 & $12.50 \%$ & 21 & $13.13 \%$ \\
\hline Total & 80 & $50 \%$ & 80 & $50 \%$ \\
\hline \multicolumn{4}{|c|}{ Mean Age: $\mathbf{4 6 . 5 3 + / - 5 . 3 5}$} & Mean Age: 47.02 +/- 5.10 \\
\hline P= 0.55 95\% CI- -1.1422 to 2.1222
\end{tabular}

The analysis of mean blood sugar levels of patients with diabetes mellitus (group A) and healthy individuals showed that the mean fasting blood sugar level (group B) was 174.26+/- 27.62 and

$84.36+/-10.02$ respectively. Whereas mean post prandial blood sugar level in group A and group B

Table 3: Mean fasting and postprandial blood sugar levels in both the groups. Paired $\mathrm{T}$ test showed difference in fasting and postprandial blood sugar levels to be significant $(\mathrm{P}<0.05)$

\begin{tabular}{|l|c|c|c|}
\hline & Group A & Group B & Significance \\
\hline Fasting & $174.26+/-27.62$ & $84.36+/-10.02$ & $\mathrm{p}=<0.0001$ \\
\hline Post Prandial & $248.32+/-38.76$ & $108.72+/-14.08$ & $\mathrm{p}=<0.0001$
\end{tabular}

The thyroid function tests showed that in group A (Diabetes mellitus type 2 cases) $54(67.50 \%)$ patients were euthyroid whereas in group B euthyroid. Either subclinical or overt hypothyroidism was seen in $25(31.25 \%)$ patients (healthy individuals) $66(82.80 \%)$ patients were statistically significant difference in mean age of both the groups $(\mathrm{P}=0.53)$. was $248.32+/-38.76$ and 108.72+/- 14.08 respectively. The difference in fasting and postprandial mean blood sugar levels in studied groups was found to be statistically significant $(\mathrm{P}<0.0001)$ (Table 2).

in group A and $13(16.25 \%)$ patients in group B, whereas overt hyperthyroidism was seen in 2 $(2.50 \%)$ and $1(1.25 \%)$ patient in group A and B respectively. There was no patient with subclinical hyperthyroidism in either of the groups.

Thyroid status in the studied cases.

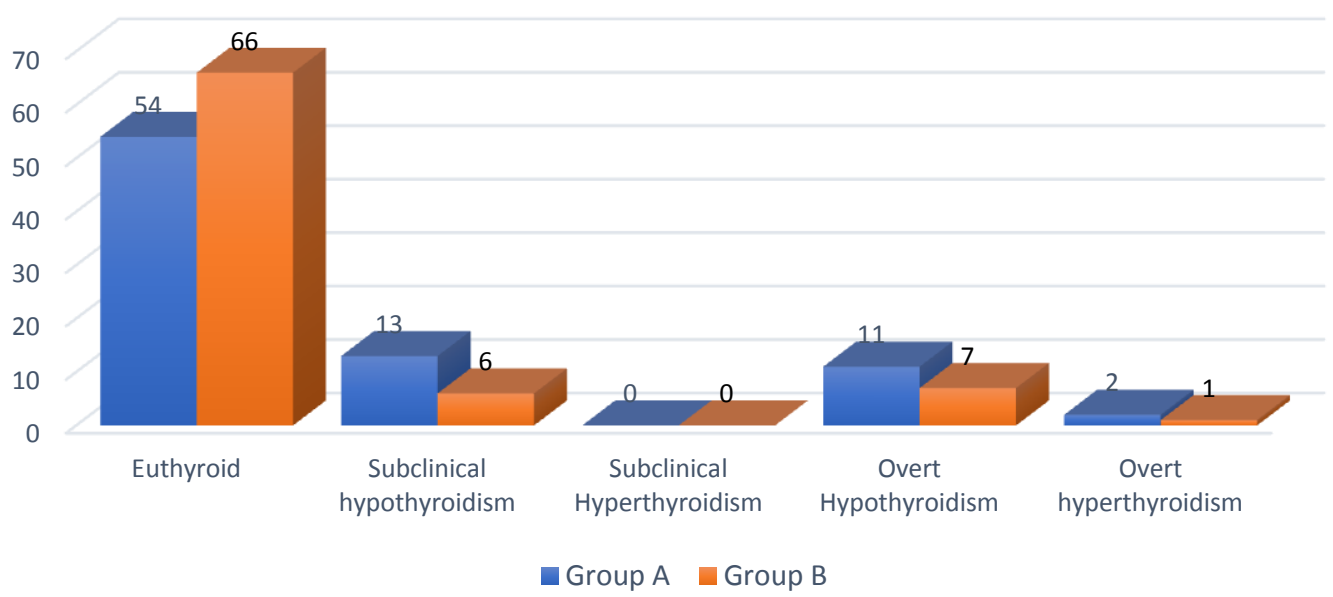

Figure 1: Thyroid Status In studied cases. 
The comparison of the patients of both the groups on the basis of whether they had a normal or abnormal thyroid function test showed that patients with diabetes mellitus type 2 were more likely to be having abnormal thyroid function test as compared to healthy individuals and the difference was found to be statistically significant $(\mathrm{P}=0.043)$.

Table 4: Thyroid status in studied groups. Paired $\mathrm{T}$ test showed difference to be significant $(\mathrm{P}<0.05)$

\begin{tabular}{|l|c|c|c|c|}
\hline \multirow{2}{*}{ Age Group } & \multicolumn{2}{|c|}{ Group A } & \multicolumn{2}{c|}{ Group B } \\
\cline { 2 - 5 } & No of Patients & Percentage & No of Patients & Percentage \\
\hline Euthyroid & 54 & $67.50 \%$ & 66 & $82.50 \%$ \\
\hline $\begin{array}{l}\text { Hypothyroidism } \\
\text { Subclinical or overt) }\end{array}$ & 24 & $30.00 \%$ & 13 & $16.25 \%$ \\
\hline $\begin{array}{l}\text { Hyperthyroidism } \\
\text { (Subclinical or overt) }\end{array}$ & 2 & $2.50 \%$ & 1 & $1.25 \%$ \\
\hline Total & 80 & $100 \%$ & 80 & $100 \%$ \\
\hline $\mathbf{p = 0 . 0 4 3}$ (Significant) & \multicolumn{4}{|l}{} \\
\hline
\end{tabular}

The analysis of mean Free T4 and TSH levels showed that the mean Free T4 levels in group A (Diabetic patients) was $1.08+/-0.32$, whereas in group B (healthy individuals) it was found to be $1.36+/-0.44$. The difference was found to be statistically significant $(\mathrm{P}<0.0001)$. Mean TSH level in Group A was found to be $5.46+/-3.12$ whereas in group B it was found to be $3.22+/$ 0.86 . The difference was found to be statistically significant $(\mathrm{P}<0.0001)$.

Table 5: Free T4 and TSH levels in studied cases. Paired T test showed difference in Free T4 and TSH levels of both groups to be significant $(\mathrm{P}<0.05)$

\begin{tabular}{|l|c|c|c|c|c|}
\hline \multirow{2}{*}{ Age Group } & \multicolumn{2}{|c|}{ Group A } & \multicolumn{2}{c|}{ Group B } & \multirow{2}{*}{ P Value } \\
\cline { 2 - 5 } & Mean & Std Deviation & Mean & Std Deviation & $<0.0001$ \\
\hline Free T4 Levels & 1.08 & 0.32 & 1.36 & 0.44 & $<0.0001$ \\
\hline TSH levels & 5.46 & 3.12 & 3.22 & 0.86 & \\
\hline
\end{tabular}

\section{Discussion}

The comparative study was undertaken to analyze whether patients with diabetes mellitus type II are prone for developing abnormalities of thyroid gland function. We compared the thyroid functions in patients with diabetes mellitus type 2 with that of age matched healthy individuals (control group).

The analysis of thyroid functions in both the groups showed that in group A (Diabetes mellitus type 2 cases) $54(67.50 \%)$ patients were euthyroid whereas in group B (healthy individuals) 66 $(82.80 \%)$ patients were euthyroid. Either subclinical or overt hypothyroidism was seen in $25(31.25 \%)$ patients in group A and $13(16.25 \%)$ patients in group B whereas overt hyperthyroidism was seen in $2(2.50 \%)$ and $1(1.25 \%)$ patient in group A and B respectively. Our study showed that patients with diabetes mellitus type 2 were more likely to have abnormal thyroid function test as compared to healthy individuals and the difference was found to be statistically significant ( $\mathrm{p}=0.043$ ).

Uppal $\mathrm{V}$ et al conducted a case control study to know the prevalence of thyroid function abnormalities in patients with diabetes mellitus. In this study 120 patients of type 2 diabetes were included along with 117 adults of the same age group and normal glucose levels as controls. Fasting blood glucose and glycosylated hemoglobin levels were significantly higher in diabetics showing a poor glucose control. Serum tri-iodothyronine values were significantly lower in diabetics. The authors found that there was a significant correlation between glycosylated hemoglobin and thyroid hormones. However, the authors found that there was no correlation between serum insulin and thyroid hormones ${ }^{11}$. 
Dimitris L et al conducted a study to find out the prevalence of thyroid dysfunction in type $2 \mathrm{DM}$. In this study 202 type $2 \mathrm{DM}$ were included. Out of 202 patients 61 were males and 141 were females, $139(68.8 \%)$ were found to be euthyroid, 33 (16.3\%) had subclinical hypothyroidism (10 males and 23 females), 23 (11.4\%) had hypothyroidism (6 males and 17 females), 4 (2\%) had subclinical hyperthyroidism and 3 (1.5\%) were hyperthyroidism cases. Maximum cases were of hypothyroidism (subclinical and clinical) seen in the age group of 45-64 years. Patients with BMI > 25 were found to be at increased risk of having hypothyroidism $(\mathrm{p}<0.016)$. On the basis of these findings the authors concluded that Prevalence of hypothyroidism was found to be quite high in type 2 DM patients above 45 years and more so if their BMI was over $25^{12}$.

The relationship between thyroid abnormalities and diabetes induced hyperglycemia is not well understood however the authors such as Chen $\mathrm{G}$ et al proposed that Insulin resistance and $\beta$ cell function are inversely correlated with thyroid stimulating hormone and there is an insulinantagonistic effects of thyroid hormones along with an increase in TSH. These observations demonstrate that insulin imbalance is closely associated with thyroid dysfunction and the phenomenon is mediated via $\beta$ cell dysfunction ${ }^{13}$. Therefor it is important from the point of view of a treating physician to know the thyroid status of patients with diabetes mellitus, particularly in those individuals who are overweight or obese $\mathrm{e}^{14}$. Treating existing thyroid abnormalities in patients with diabetes mellitus is important from the point of view of maintaining proper blood glucose levels in these individuals. There is an increased incidence of complications in patients with diabetes having co-existing thyroid abnormalities ${ }^{15}$.

\section{Conclusion}

Patients with diabetes mellitus type 2 have increased chances of developing thyroid abnormalities including hypothyroidism and hyperthyroidism. Moreover, thyroid abnormalities may increase chances of complications of diabetes mellitus. Therefore we recommend all patients with diabetes mellitus type 2 should be tested for thyroid function abnormalities and if found should be treated accordingly.

\section{Conflict of Interest: None.}

\section{References}

1. Lin Y, Sun Z. Current views on type 2 diabetes. J Endocrinol. 2010;204(1):1-11.

2. Cho NH, Shaw JE, Karuranga S, Huang Y, da Rocha Fernandes JD, Ohlrogge AW, Malanda B. IDF Diabetes Atlas: Global estimates of diabetes prevalence for 2017 and projections for 2045. Diabetes Res Clin Pract. 2018 Apr;138:271-281.

3. Lichtenauer UD, Seissler J, Scherbaum WA. [Diabetic complications. Micro and macroangiopathic end-organ damage]. Internist (Berl). 2003 Jul;44(7):840-6, 848-52.

4. Samuels TA, Cohen D, Brancati FL, Coresh J, Kao WH. Delayed diagnosis of incident type 2 diabetes mellitus in the ARIC study. Am J Manag Care. 2006 Dec;12(12):717-24.

5. Sherwani SI, Khan HA, Ekhzaimy A, Masood A, Sakharkar MK. Significance of HbA1c Test in Diagnosis and Prognosis of Diabetic Patients. Biomark Insights. 2016;11:95-104. Published 2016 Jul 3.

6. Wang W, Lo ACY. Diabetic Retinopathy: Pathophysiology and Treatments. Int J Mol Sci. 2018;19(6):1816. Published 2018 Jun 20.

7. Leon BM, Maddox TM. Diabetes and cardiovascular disease: Epidemiology, biological mechanisms, treatment recommendations and future research. World J Diabetes. 2015;6(13):1246-1258.

8. Coller FA, Huggins CB. Effect of hyperthyroidism upon diabetes mellitus: striking improvement in diabetes mellitus from thyroidectomy. Annals of Surgery. 1927;86(6):877-884. 
9. Perros P, McCrimmon RJ, Shaw G, Frier BM. Frequency of thyroid dysfunction in diabetic patients: value of annual screening. Diabetic

Medicine. 1995;12(7):622-627.

10. Franco JS, Amaya-Amaya J, Anaya JM. Thyroid disease and autoimmune diseases. In: Anaya JM, Shoenfeld Y, Rojas-Villarraga A, et al., editors. Autoimmunity: From Bench to Bedside [Internet]. Bogota (Colombia): El Rosario University Press; 2013 Jul 18. Chapter 30. Available from: https://www.ncbi.nlm.nih.gov/books/NBK45 9466/

11. Uppal V, Vij C, Bedi GK, Vij A, Banerjee BD. Thyroid disorders in patients of type 2 diabetes mellitus. Indian J Clin Biochem. 2013;28(4):336-341.

12. Demitrost L, Ranabir S. Thyroid dysfunction in type 2 diabetes mellitus: A retrospective study. Indian J Endocrinol Metab. 2012;16(Suppl 2):S334-S335.

13. Chen $\mathrm{G}, \mathrm{Wu} \mathrm{J}$, Lin $\mathrm{Y}$, et al. Associations between cardiovascular risk, insulin resistance, $\beta$-cell function and thyroid dysfunction: a cross-sectional study in She ethnic minority group of Fujian Province in China. European Journal of Endocrinology. 2010;163(5):775-782.

14. Kouidhi S, Berhouma R, Ammar M, Rouissi $\mathrm{K}$, Jarboui S, Clerget-Froidevaux MS, Seugnet I, Abid H, Bchir F, Demeneix B, Guissouma H, Elgaaied AB. Relationship of thyroid function with obesity and type 2 diabetes in euthyroid Tunisian subjects. Endocr Res. 2013;38(1):15-23.

15. Reddy KS, Pragnanjali E, Dorsanamma M, Nagabushana MV. A study of prevalence of thyroid disorders in type 2 diabetic patients in tertiary care hospital. Int J Adv Med 2018; 5:1383-7. 